International Journal of Instruction e-ISSN: 1308-1470 • www.e-iji.net
July $2020 \bullet$ Vol.13, No.3

p-ISSN: 1694-609X

pp. 877-894

Received: 27/06/2019

Revision: 10/03/2020

Accepted: $23 / 03 / 2020$

OnlineFirst:24/05/2020

\title{
The Use of Experiential Learning as a Teaching Strategy in Life Sciences
}

\author{
Genevieve Mc Pherson-Geyser \\ Ms.,University of Pretoria, South Africa, fifim7@ gmail.com
}

Rian de Villiers

Prof., University of Pretoria, South Africa, rian.devilliers@up.ac.za

Portia Kavai

Dr., University of Witwatersrand, South Africa, portia.kavai@wits.ac.za

The implementation of experiential learning within schools may hold many advantages. The objective of this study was to identify how experiential learning influences the teaching and learning of Life Sciences (biology). This qualitative inductive research focused on creating a rich amount of data through a multiple case study approach. The collection and analysis of data were done through the use of interviews, classroom observations and worksheet checklists. The interpretivist researcher in this study chose dual-medium public high schools of different socialeconomic backgrounds to participate in this study. Life Sciences teachers in Johannesburg, Gauteng, South Africa were interviewed and observed in their classes while teaching. This study showed that teachers do not fully understand the context of experiential learning. The issue that was addressed was the need for quality education by enforcing the correct use of experiential learning. The insertion of generic skills in schools will improve the development of Life Sciences learners and enable them to subsequently progress in the classroom. An experience not utilized in another area of education has not value, specifically in the Life Sciences classroom. This experience permitted learners to form a union between the outside of the classroom and the theory taught inside the classroom when testing implications. These implications can form part of experiments, subject matter or any theme related to science and society. Experiential learning sustained a gateway to the learners' outside lives, where the concepts came alive in common areas of their daily lives.

Keywords: biology, experiential learning, life sciences, teachers, teaching strategy

\section{INTRODUCTION}

The rationale of this study was to identify how experiential learning is implemented through the teaching and learning of Life Sciences (biology) in the classroom. The

Citation: Mc Pherson-Geyser, G., de Villiers, R., \& Kavai, P. (2020). The Use of Experiential Learning as a Teaching Strategy in Life Sciences. International Journal of Instruction, 13(3), 877-894. https://doi.org/10.29333/iji.2020.13358a 
researcher needs to stress that the gap in experiential learning in South Africa, as stated by Martin (2015), is the manner in which learners are taught and this break in the chain of evolving into a Life Sciences learner can only be restored through the use of experiential learning. A clear identification is needed whether teachers in the Life Sciences classroom apply experiential learning to extract the knowledge of a proficient learner. The South African educational system focuses on testing learners for its own merit rather than using such testing as a teaching tool (Ramaroka, 2007). Learners may use experiences from outside the classroom, but it will seem irrelevant in certain themes, for example, the topic mitosis in the Grade 10 Life Sciences Curriculum Assessment Policy Statement (CAPS) document. Teachers may use the implementation of experiential learning and the learners' pre-existing knowledge to generate their own experiences inside the classroom while developing optimum intelligence. The objective of the study was formulated into the following research question: How does experiential learning as a teaching strategy influence the teaching and learning of mitosis in Grade 10 Life Sciences classrooms? This objective will assist to advance teachers' knowledge and provide pertinent information on the success of this strategy (Icobucci \& Churchill, 2010).

The current status of experiential learning as a teaching strategy in public education is alarming as it was clearly identified that teachers place a certain focus or even restriction on learning by only evolving a knowledgeable learner rather than an adaptable skilled learner. If Life Sciences lessons do not encourage the necessary skills to facilitate this strategy, they resemble experiential learning without having the actual impact thereof (Andrews, Leonard, Colgrove \& Kalinowski, 2011). This is the first study of this nature within a Life Sciences, South African context. The findings from this study could help to plan for better support for teachers with regard to using experiential learning and its effective implementation in Life Sciences classrooms, showcasing the possible attributes and shortcomings that would influence the effectiveness of experiential learning as a teaching strategy. For this to take effect, one should first understand what experiential learning is and the importance thereof.

\section{Experiential Learning}

Experiential learning is a process in which new data is comprehended by the learner and transformed by means of an experience (Kolb \& Kolb, 2005). This method investigates particular components such as skills, techniques and the environment, which will ensure that the learner gains knowledge that is relevant to those particular components (Kolb 2006). True experiential learning can also be labelled as an "atmosphere" created by the teacher to enhance the learning capacity of a learner (Kolb \& Kolb, 2005, p.199). As an organisational method of learning, experiential learning, if correctly developed, planned and implemented, may progressively enhance learners' learning style and enhance teachers' teaching style. Detecting learners' challenges in certain areas in Life Sciences may ensure the effective use of experiential learning methods and is therefore characterized by the setting of increasingly challenging exercises for the learner to allow for growth during the learning process. Experiential learning focuses on the promotion of the development of a learner's potential, building on his/her strengths and taking 
advantage of his/her talents. The promotion of learner's potential should be developed through the teacher's teaching style.

\section{Learning and Teaching Styles}

Learning styles are a vortex of exclusive methods for learners in the process of acquiring knowledge. As a way of experiencing life and the strains of the environment in which learners exist, experiential learning is a preferred way of developing four learning modes (Passarelli \& Kolb, 2011). Experiential learning places the attention on the learners. Experiential learning also encourages teaching that diverges from the traditional approach to pragmatic learning (Pittaway \& Cope, 2007). In the traditional approach, the teacher is the central stream of information who drills the learners in what they have to accomplish (Wang, 2006). This method of teaching does not equip learners with the skills and competencies to cope in an ever-changing world (ibid). Learners need to develop critical thinking and life-long learning skills. Teachers must therefore rethink whether their strategies are in line with teaching learners the necessary Life Sciences' skills (Wang, 2006). It is important that teaching and learning styles are congruent so that maximum learning can take place. Learners must understand the reasons why different teaching styles are used in order to understand their own learning. Teachers should develop their teaching styles by incorporating those theories of experiential learning that will lead their in-classroom presentation of Life Sciences.

\section{Theories Underpinning Experiential Learning}

Experiential learning theories normally attempt to offer universal models of the learning process. When comparing the Experiential Learning Theory with other traditional theories, a prominent difference in the overall approach is formed. A very different outlook has arisen in education that entails the proper relationship between learning, work and other life activities and the creation of knowledge itself (Kolb \& Kolb, 2005). For the purposes of this study, the experiential learning theories of Kolb (1984) and Dewey (2001) were examined in order to identify the elements that influence learning and teaching in Life Sciences. Kolb focuses on experiential learning as a dimensional (a choice) assisting the process of learning, whereas Dewey provides a unique twist in inductive and deductive reasoning.

Kolb's Theory of Experiential Learning is considered to be one of the most important experiential learning theories, particularly his experiential learning model. This theory is based on learning through experiences and learners basing their choice on past experiences (Sternberg \& Zang, 2000). Kolb's Cycle of Experiential Learning model was useful in this study as it explains and categorizes a learner's learning style, which in turn may impact teaching styles. Kolb's model is divided into two modes of acquiring experience, namely, concrete experience and abstract conceptualization and two modes of transforming experience, namely, reflective observation and active experimentation (Chapman, 2006). According to Kolb, the model and stages of the model follow an easily understandable sequence that a leaner can enter at any stage (McLeod, 2010). Effective learning can only take place when the learner is able to execute all four stages of the model (ibid.). 
Dewey states that among the uncertainties, the main qualm resides in the relationship between education and personal experience (Kolb \& Kolb, 2005, p. 199). He uses the term "reflective thought" to describe the process through which people learn from their observations and personal experiences (Roberts, 2006, p. 17). He concludes that progression through the learning process means moving from inductive to deductive reasoning (ibid.). Dewey's model describes learning as an impulse of concrete experience and evolving the learners' knowledge into high-order purposeful action. Dewey's approach to incorporating all stages can be interpreted by the way the stages are enmeshed. The learner comes around to gaining an impulse where an observation is required to obtain knowledge. Dewey's model is known for its cyclic advances of learning by incorporating each phase of impulse and judgment, knowledge and observation. For a learner to go through the learning process and reach the deductive reasoning process, a learner must go through these four mentioned stages (Alberta Education, 2010; Passarelli \& Kob, 2011). The main qualm that Dewey's model addresses is the link between a singular source (the teacher) and habitual style of thinking (McLeod, 2010). Dewey suggests that routine in methods and styles predicts a type of weakness in knowledge that should be exchanged with a reconstructive reflective thought that carries weight into deeper thinking. The aim of cyclic advances from impulse to judgment and knowledge to observations is that it makes a distinction between experiences such as composed interaction and reflective thought. Learner growth can only stem from failure or the pressures of moving out of one's comfort zone through primary experiences, which will give rise to reflective thought (Miettinen, 2000).

Experiential learning revolves around the notion of taking action (Clark, Threeton \& Ewing, 2010). When combining these different theories, the following conclusion can be made regarding the elements that influence teaching styles in the Life Sciences classroom: learning must be based on learners' previous experiences; learners must have time to think about their experiences and reflect on them; and they must apply their new skills in real-life situations (Enfield, 2001). A combination of both Kolb (1984) and Dewey's (2001) models as a conceptual framework were used in this study. Figure 1 summarises the four stages of experiential learning.

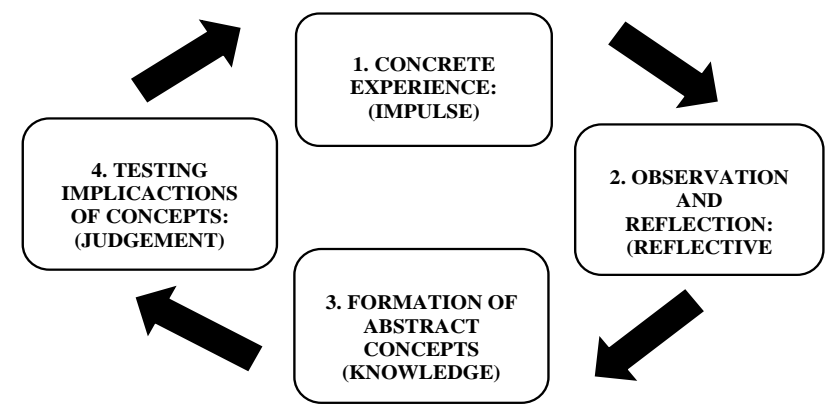

Figure 1

A combination of Dewey's (2001) and Kolb's (1984) Models of Experiential Learning 
Each angle of the model contains a certain aspect that adds value to qualitative research on experiential learning. The model has the following attributes:

- Concrete experiences: Learners are stimulated through removing their comfort zone of knowledge and placed into a new situation without bias. The learner must experience what it is he/she does not understand within the context.

- Observation and reflection: Utilizing the new knowledge from transferred experiences and practical skills in the classroom that have stemmed from processing how learners 'do' things by relying on the observations made during the concrete experiences stage. The learner has to base the situation on what occurred in previous/similar situations in the past, activating his/her prior knowledge.

- Formation of abstract concepts: Abstract concepts focus on the relation of discoveries and logically sound theories. Abstract conceptualisation discovers relationships to known theories.

Testing the implications of concepts: Active experimentation connects what the learner has learned to the real world. The leaner now applies what he has been taught.

\section{METHOD}

A qualitative research approach within an interpretive paradigm and a collective case study (Merriam, 2009) were employed to address how experiential learning influences the teaching and learning of Life Sciences.

\section{The Research Site, Sample and Participants}

The research site encompassed dual-medium public high schools in Johannesburg, Gauteng (a province in South Africa). Four schools (one urban, one peri-urban, one township and one rural school) and eight Life Sciences teachers (two from each school) were identified to participate in this study. Purposive sampling was used to select the teachers in the Gauteng Province. The demographics of the teacher sample is summarized in Tabel 1. The selection criteria were that they should be Grade 10 (the third year of public high school) Life Sciences teachers and secondly, they should have knowledge regarding experiential learning. Convenient sampling was also used because the target population was geographically suited as the target sample could be sampled quickly, it was flexible, and it saved time and money. The main objective of sampling was to represent a particular group as a way of enhancing transferability. Data saturation occurred after the interviews and classroom observations of eight teachers.

\section{Data Collection Instruments}

Three instruments were used in this study namely semi-structured interviews, classroom observations and worksheet checklists. The teachers took part in in-depth, face-to-face, semi-structured interviews. Open-ended and closed-ended interview questions were developed to solicit the teachers' demographic information; the teachers' understandings of the theories that underpin experiential learning; and the teachers' experiences of how experiential learning influences teaching and learning in the Life Sciences classroom. Only one interview per participant was held and the average length of the interviews was approximately 20 minutes. The research complied with the ethical guidelines laid down 
by the researchers' universities for educational research, including confidentiality, anonymity, voluntary participation, informed consent, and trust and safety in participation. To ensure confidentiality and privacy in this study, the schools' and teachers' names were replaced with pseudonyms or codes. The teachers were observed over a double period (50 minutes) to determine how they incorporated experiential learning on the topic 'Mitosis in plants' in their classes. It was expected from the teachers to compile a worksheet that achieved the following four outcomes of experiential learning: (1) Learners should show knowledge about mitosis in plants through a simulation; (2) Learners should be able to show their understanding of mitosis in plants through the analysis of the simulation; (3) Learners should apply knowledge and analytical skills to theory; and (4) Learners should be able to apply mitosis to science and society. An observation checklist was adapted from the Faculty Affairs Committee (2013). The researcher coded the observations manually. All notes were recorded on the checklists which was combined as an outline of precise circumstances and events that took place during the observations. Themes that recur were identified while being accompanied by a frequency table of each participants' response. Credibility was obtained through detailed descriptions of the teachers' and classroom actions, assumptions and procedures. Consistency of these observations were affirmed through cross-checking of the different instruments. Observations were done through note-taking and enhanced through a pre-written observation checklist. The validity of the instruments was ensured by acquiring advice from professionals in the same field to assist in the development, as well as the cross-checking of the different instruments.

\section{The Data Analysis Procedure}

Predetermined themes played a major role in the data analysis procedure. The interviews were audiotaped and transcribed verbatim after the data were analysed qualitatively through the use of AtlasTi. This approach made sure that the participants' views are clearly set from an interpretivists perspective to unveil the experiences through their real-world stories. Concepts were grouped together into categories and themes through which inductive codes emerged from the data (Nieuwenhuis, 2008), which ensured that important statement were captured to aid the research. Classroom observations were analysed according to the principles of Neuman (2007). Both instruments, interviews and classroom observation checklists, were analysed by utilizing predetermined questions or themes to identify accurate procedures, actions and interpretations of experiential learning.

\section{Quality Assurance of the Research Instruments}

The interview protocol was piloted on two teachers from one school to verify its validity before it was used in the main study. To ensure trustworthiness, the interviews were audio-recorded in order to obtain accurate and relatively complete records (Rule \& John, 2011). The transcriptions of the interviews were crosschecked with the participants and amended accordingly where necessary. The participants were kept anonymous throughout the research. Direct quotations from the participants were used to produce credible and convincing data. Classroom observations were strengthened through the implementation of confidentiality, credibility and the validation. Experts in the field of Life Sciences, were involved to ensure that the study was valid. All the 
instruments used were analysed to ensure adherence with the code of ethics formulated by the University.

\section{FINDINGS}

\section{Participants' biographical data}

The following table (Figure 2) summarises the biographical data from each participant as gathered through the introductory questions in the interview schedule.

\begin{tabular}{|c|c|c|c|c|c|}
\hline Pseudonyms & $\begin{array}{l}\text { Nature of } \\
\text { School }\end{array}$ & Gender & Age & Highest qualification & $\begin{array}{l}\text { Years' teaching } \\
\text { experience }\end{array}$ \\
\hline Lucy & Urban & Female & $41-50$ & Education Diploma & $1-5$ years \\
\hline Sophie & Urban & Female & $41-50$ & $\begin{array}{l}\text { Non-related educational } \\
\text { degree }\end{array}$ & $21-25$ years \\
\hline Riley & Peri-urban & Female & $41-50$ & BEd Honours & $11-25$ years \\
\hline Mia & Peri-urban & Female & $41-50$ & $\begin{array}{l}\text { Non-related educational } \\
\text { degree }\end{array}$ & $1-5$ years \\
\hline David & Township & Male & $41-50$ & BEd & 21-25 years \\
\hline Mary & Township & Female & $41-50$ & Bed & 21-25 years \\
\hline Lisa & Rural & Female & $21-30$ & BEd & $1-5$ years \\
\hline Garry & Rural & Male & $21-30$ & BEd & $1-5$ years \\
\hline
\end{tabular}

Figure 2

Biographical Data of the Teachers that Participated in This Study

A variety of socio-economic schools were included in the study to ensure a rich amount of data in the implementation of experiential learning. The schools were coded according to their socio-economic statuses, which included an urban school, peri-urban school, township school and a rural school. The schools were ranked according to the level of resource availability of the school community (Department of Basic Education, 2015). Schools are placed between a 1 (mostly funded by government) and a 5 (funded by the learners' school fees) quintile system.

School A is an urban school and is fully funded by the learners' school fees. School B is a peri-urban school and is partially funded as the government contributes $25 \%$ of the school's funds. The school then further relies on the learners' school fees. School C is a township school and is funded $50 \%$ by the government where the rest is substantiated through the learners' school fees. School D is a rural school and is fully funded $(100 \%)$ by the government.

\section{Interviews}

Influences of experiential learning with regard to teaching and learning

After the collection of the data, themes, sub-themes and categories were created as a reduction phase in AtlasTi. The theme was grouped into five sub-themes, namely, enhance learning, enhance teaching, influences contributing to the use of experiential learning by the teacher, traditional methods and performance.

Enhance learners' learning experience

Enhanced learning includes the presence of outside experiences and their usefulness in the Life Sciences classroom. Regarding the knowledge of the topic of mitosis, learners showed comprehension through making links and storing the content in their long-term 
memory. This sub-theme was grouped into three categories, namely, learners' attitudes, long-term knowledge and experiences.

- Learners' attitudes towards experiential learning

In the case referenced below, Sophie's practical beliefs in learning were shown through the excitement of the learners when taking part in the lesson. The excitement of teachers normally transfers to the learners, which equally stimulates the attitude of both involved.

The learners are really excited if you place things out (experiments) and show as it stimulates them more to inquire. A lot of them will come the next day and say "teacher we saw" or "we looked for" which stimulates them more (Interview transcript 2:12) [Translated].

Mia explained in her teachings that the learners loved practicals and she further detailed how their attitude changed to the enhancement of the learning experiences.

- Long-term knowledge of subject content

Superficial knowledge that is only for assessment purposes is not of any benefit, but rather to enhance long-term knowledge for a skilled learner with a deep understanding (Sims, 2006). Mia stated clearly that learners stored their understanding in their longterm memory and started to associate the subject content with reality when implementing experiential learning.

- Experiences developed through experiential learning

Sophie explained the essence of the newly attained experiences supplemented to the already developed experiences as the learners attended a field camp from which they brought back information and photos on a previously taught topic. They were excited to share it not only with the teacher, but also with the other learners in the classroom. This enthusiasm was showed in her answers during her interview and the way in which she reacted to her learners:

We were climbing out there was a lot of moss, and they immediately shouted "teacher, look at the moss, look at the moss!" Do you understand, they would not have seen that moss if we did not do it in the particular way in the classroom of how it really looked...they would have walked over it and would not have known what it is (Interview transcript 2:19-25) [Translated].

Sophie also focused on the fact that everything was observable, and because an experience was built, they effortlessly recalled the work that had been completed. The participant Riley confirmed that learners appreciated the time given to explore by themselves and that there was time for them to grab this opportunity. Finally, Lisa explained that the advantages of experiential learning in the classroom led to exposure to different environments and strategies. Exposure then led to the formation of new experiences that could be used in another theme.

\section{Enhance Teachers' Teaching Styles}

The relationship between the enhancement of learning and teaching was clear and closely related. When a learner appreciates, develops, progresses or grasps a certain theme or skill, it boosts the teacher in their teaching practices as well. This sub-theme is 
grouped into two categories, namely, control in the classroom and increased intelligence.

- Control of learners' skills

Sophie had already explained that experiential learning enhanced the learners' experiences, but further mentioned that when their experiences were enhanced by actually seeing what they had been doing in class at the camp, she felt the fruits of her labour as an enhancement of her teaching. Riley addressed the enhancement of her teaching though explaining that results should be better at the end of the day when implementing experiential learning as it allows a teacher to monitor what they can do, what skills they have developed and what they should focus on. Riley explained:

You see, you're able to concentrate on a smaller number. You're able to get the result at the end of your day. You see, it becomes effective because you're able to monitor what they do, you're able to test whether they've been able to acquire the skill (Interview transcript 3:18).

- Increased intelligence of learners' subject knowledge

Mary mentioned that a hands-on experience would create opportunities for learners to apply what they had learnt. In this case, experiential learning ensured that the learners not only showed interest in the activity but also remembered what they had done, enhancing this teacher's teaching, which made her feel smarter.

Influences contributing to the use of experiential learning by the teacher

Teachers' implementation of experiential learning is influenced by factors such as the development of their professional knowledge, their self-efficiency, intentions and their attitudes.

- Elementary (development of basic knowledge)

One of the most straightforward answers regarding the use of experiential learning was that it made their life easier in teaching the topic, developing the necessary skills and connecting different themes. The objective of experiential learning is to allow the teacher to make more connections, teach more skills and not feel pressure under the load of what is needed to be attained by the learner through the teaching. In support of this, Mary explained: It really makes my life easier (Interview transcript 3:20).

- Lesson synopsis

Riley was very passionate about the fact that experiential learning gave her an opportunity to summarize everything that she had been teaching into one lesson which she could use again in the same manner.

- Self-discovery of cross-curriculum

David explained that the strategy worked as an educational tool. He understood the topic and made connections between themes in teaching the curriculum. There are many factors that contribute to the implementation of experiential learning, these include teacher and learner enhancements, making the teacher's life easier, understanding the topics with a greater depth of knowledge and the summarization of content into a practical where knowledge, skills and connections can be assessed in one lesson.

International Journal of Instruction, July $2020 \bullet$ Vol.13, No.3 


\section{Traditional Methods}

Teachers that focus on lecturing and demonstrations are more invested in using a traditional approach where the docility of the learner is promoted to ensure quick content input. The teachers in this study believed that experiential learning is a better way of teaching as it promotes the improvement of transferring content to learners. Rather than only writing and talking, learners experience the content being taught by touching, allowing them a more holistic understanding of the content. This sub-theme is grouped into three categories, namely, platform formation, active involvement and advancement through experiential learning.

- Platform formation of learners' basic knowledge

Lucy explained that she still required her learners to memorize different facts but tried to teach a few skills when doing experiments. In this case, the teacher was the source of the experiment, and learners were not involved in any aspect and were only required to memorize what was being covered in class and produce it when requested. Many teachers see this as a practical experience because the teachers feel involved and apparatus is taken out of the storeroom to initiate interactivity.

- Active involvement of learners

Traditional methods do not allow for active involvement and therefore learners tend to sleep in class time. Riley was honest in saying that if learners take part in mundane routines in the classroom, they will quickly lose attention and interest in the lesson:

To be honest while we teach sometimes, some of them are asleep. Understand? But when we did the experiment, they were active participants, they actively. To touch, you understand? So it's allows them to be able to, you know, to participate (Interview transcript 3:19-22).

David adamantly stated that Life Sciences cannot be taught without experiments and if it forms the bulk of teaching (information) it is no longer science. Mary elaborated further on David's explanations by adding that skills are developed when doing experiments. When a learner is forced to swim or drown, so to speak, what they learn and the skills they attain will never be forgotten. She furthered her reasoning stating that when using traditional methods, learners write without understanding but with experiential learning they engage with the content being taught.

- Advancement through experiential learning

Advancement through experiential learning means outcomes are achieved in a completely different manner to traditional teaching methods. Mary agreed that experiential learning is better than traditional teaching as she found traditional methods to be boring; she further explained that without experimenting, a learner loses concentration. Lisa shared that she understood that experiential learning is not the same as traditional learning, which she referred to as the 'chalk and talk' method: Because in science, you have to experience what you are learning about (Interview transcript 7:1314).

Garry referred to traditional methods as the old-school way of teaching and explained that experiential learning is a modern teaching technique. The performance of learners 
was noticeably better when using experiential learning in the Life Sciences classroom so much so that the teachers themselves were shocked at the teachers needs to change with the times. Garry also referred to the use of old-school methods and that it is up to each teacher to change the way in which teaching and learning is conducted in their classroom.

\section{Learners' Performance Level}

The enhancement of learner performance level of outcomes achieved. This sub-theme is grouped into three categories, namely, the betterment of outcomes, attitude of completion, and dual success.

- The betterment of learning outcomes

Sophie testified that there was an immediate difference and that betterment could be seen at the end of a lesson using experiential learning or when an outcome was achieved: It immediately improves the outcome (Interview transcript 2:29) [Translated]

- Learners' attitude of completing tasks

Riley confirmed the eagerness of the learners to complete tasks after a skill had been successfully developed: They got the skills, immediately, like I said. You could see the activeness in the kids (Interview transcript 3:23).

- Dual success in performance

Mia explained that when it comes to assessment practices, everything they had been doing practically was also tested theoretically thus the reaping of success came from both sides of the academic spectrum. She explained: Of course, it does because when it comes to the exams, uh, the very same things that they are doing practically (Interview transcript 4:15).

Mary was clearly astonished at the results gained after implementing experiential learning as her learners were able to recall what they had heard and could produce what they understood in their own words. This indicates that results were improving, and learners were developing a new skill of interpreting information and producing quality work.

\section{Classroom Observations for the Four Modes of Experiential Learning Modes of experiential learning in the classroom observations}

The following four modes were used to evaluate the teachers with an observation checklist during their lesson on mitosis. The teachers were evaluated on their scaffolding through concrete experiences, their initiation of reflective thought through reflection and observation, their examination of analytic skills through the formation of abstract concepts and finally, testing the implications of concepts.

Concrete experiences: Gaining baseline knowledge

Concrete experiences must be coupled with a stimulus, whether it is feeling, hearing or seeing, there should be a continuous interaction factor in a Life Sciences lesson. Stimulation allows for learners' success in gaining knowledge and developing skills during these mitosis lessons. This stage focuses on the basic knowledge that a learner should gain through a simulation on mitosis in plants. Four teachers (Lucy, Sophie, 
Mary and David) opted to use a video. Sophie used the simulation as an introduction, whereas David and Mary utilised it as a type of clarification. The videos did not allow any independent thinking as they answered the questions of the worksheet in chronological order, which could only have developed learners' skill in taking accurate notes.

The interactiveness of simulation is not promoted in Life Sciences classrooms. Some teachers, such as Riley, used clay representations built by the learners, and Sophie allowed the learners to look through microscopes as a reference to a practical. Due to resource shortages, six teachers tried to show and explain as clearly as possible on the practicality of mitosis. Scaffolding, knowledge and understanding of the basic measures of mitosis were clear in all of the teachers' lessons. Riley supported the learners' answers through extracting knowledge on previous themes in the Life Sciences curriculum such as the basic dividing restrictions of a cell, as well as the learners' experiences with topics such as genetic modified foods, which focused more on plants. Five teachers did not mention mitosis in plants at all.

Observations and reflections

Observations are a mode of transforming concrete experiences and practical skills developed in the Life Sciences classroom. This action monitors experiences through reflection to show understanding through analysis. The outcome that the teacher should strive for in this section is that the learners should show their understanding of mitosis in plants through the analysis of the simulation. Two teachers (Lucy and Sophie) had access to microscopes and even displayed these to the learners. Lucy, on the one hand, displayed the microscopes without encouraging the learners to touch or observe the mitosis phases. Sophie, on the other hand, used a worksheet that forced learners to observe but she did not explain to them how it worked. A lack of resources interfered with the practical aspect of the lesson. Three teachers (Riley, David and Garry) did not let the lack of apparatus discourage them as they tried as far as possible with videos, pictures and intricate explanations to provide observations of micrographs as if it were under a real microscope. Mia, Mary and Lisa carried out their observations through the pictures on the worksheets. Sophie, Riley and Mary showed an acceptable reflection on the observations with appropriate questioning and worksheets. Five teachers depended on the worksheet as an approach to reflection in order to monitor the learners' understanding.

\section{Formation of abstract concepts}

Abstract concepts are formed in relation to new discoveries or links found in the Life Science curriculum to other themes. The focused outcome in this stage is that learners should be able to apply their knowledge and analytical skills to theory. Understanding this mode and developing its skills is built from concrete experiences, as well as observations and reflections and use this newly found knowledge as a method to discover even more knowledge. It was clear that this mode was not developed at all in the participating classrooms. Discovery was never consciously administered in the classroom, Lucy referred to open wounds and the healing thereof, which led to a strand of discovery. Riley was excellent at stimulating discovery and eliciting knowledge on 
previous themes and experiences with Life Sciences in her classroom. Even though David did not incorporate discovery in his analysis of the cell cycle and the learners' understanding of it, specified data allowed the learners to draw on knowledge and the relationship of mitosis' function and division. Five teachers lacked skill development and knowledge transformation of the discovery of theories pertaining to mitosis as a theme.

Testing implications of concepts

Learners should be able to apply mitosis to science and society. Learners should be able to see the value of this particular theme and how it can be linked to reality, meaning the use of their own experiences from their everyday lives to understand and represent mitosis. The higher-order thinking skills of Bloom's taxonomy are essential in the application of concepts, which is the final step in monitoring the learners' understanding and pushing them beyond that which is required. The judgement stimulated by Sophie, Riley, Mia and Garry was acceptable in their questioning at the end of the lesson. They did not teach a skill or push the learners beyond mere conceptions, but rather asked random questions or drew on previous experience. Half of the teachers covered some judgment aspect but reverted to answering the stated question for the learners, which did not allow the learners to learn a skill or gain the knowledge needed. The problem with this category was that the teachers allowed too much time for scaffolding and recapping of common, easily discoverable knowledge than focusing on skill development and inspiring the relationship between science (Life Sciences) in the classroom and society (experiences of outside the classroom).

\section{DISCUSSION}

The teachers who participated in this study were asked to elaborate on how they knew that experiential learning was effective. Three sources of substantiation were intertwined, namely, the worksheets designed by the teachers, the classroom observations, and the reflection from the researcher. Within the worksheets, the teachers referred to formative assessment that either contributed to the year mark or not, or summative assessments. Evidence from the worksheet includes the learners' understanding of concepts better through scaffolding; their ability to answer higherorder thinking questions that adhere to Bloom's Taxonomy; their skills development, which creates associations between sciences and society; and learners referring to experiential learning experiences during the worksheet. The main objective of experiential learning is to enhance the learning experience of the learner (Bantwini \& McKenzie, 2011; Moon 2004). 'Enhance learning' includes both the surrounding factors that evolve in the classroom and the long-term development in cognitive recognition.

Prior experience is a fundamental part of learning and what is brought into the classroom. The range of learner experiences enriches the classroom and the teaching strategies used when introducing experiential learning. These strategies assist the learners to utilise their experiences obtained prior to entering the classroom with the same guidance concepts taught in the classroom. Reflection enhances the learning process; however, experiences loses meaning unless the experience is related to and valued in another area of education. Reflecting on the experiences drawn from outside 
the classroom created a union between this and the theory taught inside the classroom when testing implications. Reflections further allows the principles taught in the classroom to be harnessed in these learners' real-world situations. The essence of what is important is extracted when the abstract concepts become concrete when achieving the four modes of experiential learning.

Experiential learning bring notions into a holistic view that is sustained by the learners' outside lives, where the concepts come alive in common areas of their daily lives. For an influence to be successful, a learner should be mentally engaged and ready to learn. This connection increases knowledge retention. Cases were identified where experiential learning procedures were not successfully utilised in the observed classroom as learners struggled to internalise the concepts and make them their own. Biggs (2006) explains that teachers implementing a specific theory, in this case Experiential Learning Theory, generally present their teaching decisions in line therewith. This theory aims to create an environment that enhances teachers' proficiency in the subject of Life Sciences, ensure self-development, and contribute to the feeling or attitude of the success of a learner capturing a certain theme or skill at any given time. The way in which the teacher perceives a learning strategy is seen as one of the key influences in their practice (Bantwini \& McKenzie, 2011; Chisholm, 2005). Mata (2012) indicates that the properties of the curriculum can necessitate change in teaching through the medium of experiential learning with the focal purpose of enhancing not only learners' learning experiences, but also the teacher's experiences when teaching. This sub-theme is grouped into three categories, namely, elementary, lesson synopsis and self-discovery.

Transforming knowledge is the main aim that is accomplished through experiential learning. Transformative learning is the "process of making a new or revised interpretation of the meaning of an experience, which guides subsequent understanding, appreciation, and action" (Prithishkumar \& Michael, 2014). A critical reflection on learners' experiences continuously transforms their knowledge and learning experience. The learners' worksheets only reflected on previous experiences when examining mitosis in a new light. When learners were required to revise their interpretations of mitosis, and ultimately made a conscious choice to change or transform their way of thinking by applying their knowledge to a skill such as interpretation or judgement, a positive effect is seen in the results achieved. This study provides valuable insight on the current status of experiential learning as a teaching strategy in public education as it is clearly identified that teachers place certain focus or even restriction by only evolving knowledgeable learners rather than an adaptable skilled learner.

One of the main objectives of this study was to investigate whether experiential learning had any positive impact as a learner-centred teaching method rather than teachers reverting back to any traditional methods. Experiential learning supports molding a competent and knowledgeable Life Sciences learner (Georgiou, 2005). Change in the Life Sciences classroom can be attained through experiential learning as this strategy enriches overall classroom performance (Weltman, 2007). As a teacher, the aim is not to create a superficial understanding of Life Sciences, but rather to encourage the retention of long-term knowledge, which, in retrospect, allows for the amelioration of learners' performance (Sims, 2006). 


\section{Contributions in terms of the conceptual framework}

The conceptual framework lacked in coherence and completion in the lessons observed. A clear gap in the Life Sciences classroom was evident in the modes of the Mitosis lesson. The conceptual framework (see Figure 1) shows that the modes should be incorporated to maximise learning, which will extend from theory to practice. Following the outline of the framework, it provides an understanding of the four modes of experiential learning in the context of the curriculum. The teachers' understanding, motivation, challenges and successes were addressed in the interview schedules, which allowed the teachers to form a renewed perspective of this strategy before they attempted to provide proof of their understanding of experiential learning in their observed lessons. The quintessential factor that has emerged from the conceptual framework was that the teachers only focused on concrete experiences. A double period of approximately 50 minutes was used solely for understanding the theme at hand, it was seen as an isolation factor which showed that the learners could not practice skills in the theme if they do not understand the topic at a level that is acceptable in an assessment. It was clear that the teachers were comfortable being the only source of information in the classroom and did not trust the learners to discover certain facts or develop knowledge on this theme that would lead to higher-order thinking skills. It is important to teach Life Sciences across the curriculum in order to incorporate themes as well, and to override the challenge of time constraints. It is worth mentioning that the teachers definitely achieved the first mode but lacked in applying the other three modes as represented by the conceptual framework. Judgement was never stimulated by the teacher as rehearsed answers were given by the teachers and learners were never allowed to discover knowledge on their own. It could be concluded that the teachers did not hold the necessary skills to lead the classroom to judgement or have the experience to successfully implement the final mode of the conceptual framework. Finally, a very important finding from this study was that the influence of experiential learning in the Life Sciences classroom in specifically supporting the understanding of the theme, the skills developed and the overall discovery of other themes that are built on the current theme in the classroom is vital. Immediate effect was the aim of the teaching in the lesson observations. The participants did not focus on the long-term development of a skilled learner who could apply the same type of skills to different topics and discover new knowledge independently from the teacher. As already mentioned, in identifying the gap in knowledge (Wenger, 2012) of experiential learning in South African schools, the researchers studied teachers regarding their knowledge of the strategy of experiential learning and the use thereof in their classrooms to learn from them or collaborate with the intention to learn.

\section{Limitations and directions for future research}

It is not possible to generalise the conclusions made in this study but rather, we were able to create a body of knowledge that will generate new research questions to further research on experiential learning. The teachers' lack of understanding and confidence in the implementation of experiential learning in the classroom is a limitation in itself. 
Most of the teachers focused on one mode of experiential learning throughout their lesson, which made the comparison between use and disuse minimal.

Future research should start by noting the limitations of such research, include the investigation of other experiential skills, as well as themes pertaining to the Life Sciences curriculum, such as: the planning and organising of the lesson plans of the teachers; life-long learning for teachers in the development of experiential learning; initiative from teachers in the application of experiential learning; teachers' willingness to use experiential learning; and the promotion of technology in the use of experiential learning. Future research could focus on a tool that teachers can access in order to plan, organise and evaluate whether a specific theme or topic in any practical classroom reaches all four modes of experiential learning effectively, efficiently and with a higher percentage of success in developing a skilled learner.

\section{CONCLUSION}

The upsurge of experiential learning and its implementation in the Life Sciences classroom was investigated in this study. The interplay between the instruments allowed the study to evolve in a manner where definite obstacles were identified in the teaching of Life Sciences. The reaping of positive results in using experiential learning gave way to a new teaching dimension which will motivate teacher to implement experiential learning in the Life Sciences classroom. It is hoped that all teachers will realize the importance of the use of experiential theories as a base to understand the strategy and correctly implementing the strategy in the Life Sciences classroom. The promotion of learners' skills which ensure a proficient learner in all the levels of Bloom's Taxonomy as required by the Curriculum Assessment Policy Statement. This study shows that schools need to furthermore investigate this gap in teaching. The research highlighted the positive influences on the teaching and learning of Life Sciences through four modes while combining the conceptual framework of Kolb (1984) and Dewey (2001), such as concrete experiences (impulse), observations and reflection (reflective thought), the formation of abstract concepts (knowledge), as well as testing the implications of concepts (judgement). Furthermore, it is hoped that teaching methods will be developed through combining these four modes as to enhance the teaching of all learners. However, it is important that teachers bear in mind that this strategy is a continuous effort, which includes an ambition for lifelong learning. When catering to a vast amount of learners with different styles, it is good to be well-equipped with the necessities to shift from traditional methods to experiential learning (Prithishkumar \& Michael, 2014). This study showed that, despite shortcomings and limitations, there is a need for further research that will allow teachers to overcome the obstacles encountered when using experiential learning.

Internationally this study can explore the impact of experiential learning within education as it introduces more innovative experiential strategies and their effectiveness. Incorporating the techniques in this study to international education can enhance the pedagogy and curriculum in facilitating active learning (Paul \& Mukhopadhyay, 2008). In conclusion, the use of the Experiential Learning Cycle maximized the time and manner of learning in the Life Sciences classroom. 


\section{REFERENCES}

Alberta Education. (2010). Inspiring education: A dialogue with Albertans. Edmonton, AB: Alberta Education.

Andrews, T., Leonard, M., Colgrove, C. \& Kalinowski, S. (2011). Active learning 'not' associated with student learning in a random sample of college biology courses. Cell Biology: Life Sciences Education, 10(4), 394-405.

Bantwini, B., \& McKenzie, E. L. K. (2011). District officials' assumptions about teacher learning and change: Hindering factors to curriculum reform implementation in South Africa. International Journal of Education, 3(1), 1-25.

Biggs, J. (2006). Enhancing teaching through constructive alignment. Australia: Kluwer Academic.

Chapman, A. L. (2006). Solving the puzzle of deliberate self-harm: The experiential avoidance model. Behaviour Research and Therapy, 44(3), 371-394.

Chisholm, L. (2005). The making of South Africa's national curriculum statement. Journal of Curriculum Studies, 37(2), 193-208.

Clark, W. R., Threeton, M. D., \& Ewing, J. C. (2010). The potential of experiential learning models and practices in career and technical education. Journal of Career and Technical Teacher Education, 25(2), 45-62.

Department of Basic Education, South Africa. (2015). School masterlist data. Pretoria: Department of Basic Education. Retrieved from http://www.education.gov.za/EMIS/EMISDownloads/tabid/466/Default.aspx

Dewey, J. (2001). Theory of experiential learning. Western Collage, MO: Missouri.

Enfield, R. P. (2001). Connections between 4-H and John Dewey's philosophy of education focus. California: University of California.

Faculty Affairs Committee. (2013). Instructional checklist. Retrieved from http://www.formsbirds.com/free-instructional-observation-checklist.

Georgiou, P. I. (2005). A case study in classroom experiential learning of problem structuring methods. Journal of Operational Research Society, 1, 1-70.

Kolb, A. V., \& Kolb, D. A. (2005). Learning styles and learning spaces: enhancing experiential learning in higher education. Academy of Management, 4(2), 193-212.

Kolb, D. A. (1984). Experiential learning: Experience as the source of learning and development. Englewood Cliffs: Prentice-Hall.

Kolb, D. A. (2006). Experiential learning: Experience as the source of learning and development. Englewood Cliffs, NJ: Prentice Hall.

Martin, D. E. (2015). Bridging the experiential learning gap: An evaluation of the impacts of Ulster university's senior student tutoring scheme on first year students. Journal of University Teaching and Learning Practice, 12(2), 1-17.

Mata, L. (2012). Key factors of curriculum innovation in language teacher education. World Academy of Science, Engineering and Technology, 66, 512-520. 
McLeod, S. (2010). Kolb-learning styles. Retrieved from www.simplypsychology.org/learning-kolb.html.

Merriam, S. B. (2009). Qualitative research: A guide to design and implementation. Revised and expanded from qualitative research and case applications in education. California: Jossey-Bass.

Miettinen, R. (2000). The concept of experiential learning and John Dewey's theory of reflective thought and action. International Journal of Lifelong Education, 19(1), 54-72.

Moon, J. A. (2004). A handbook of reflective and experiential learning: Theory and practice. New York: Routledge Falmer.

Neuman, W. L. (2007). Basics of social research: Qualitative and quantitative approaches. Needham: Pearson.

Nieuwenhuis, J. (2008). Qualitative research designs and data gathering techniques. In K. Maree (Ed.), First steps in research (pp. 70-92). Pretoria: Van Schaik.

Passarelli, A., \& Kolb, D. A. (2011). Using experiential learning theory to promote student learning and development in programs of education abroad. Cleveland: Stylus.

Paul, P., \& Mukhopadhyay, K. (2008). Experiential learning in international business education. Journal of Teaching in International Business, 16(2), 7-25.

Pittaway, L., \& Cope, J. (2007). Simulating entrepreneurial learning integrating experiential and collaborative approaches to learning. Sage J Pub, 38(2), 211-233.

Prithishkumar, I. J., \& Michael, S. A. (2014). Understanding your student: Using the VARK model. Journal of Postgraduate Medicine, 60(2), 183-186.

Ramaroka, N. J. (2007). Educators' understanding of the premises underpinning outcomes-based education and its impact on their classroom assessment practices. Pretoria: University of Pretoria.

Roberts, G. (2006). A philosophical examination of experiential learning theory for agricultural educators. Journal of Agricultural Education, 47(1), 17-29.

Rule, P., \& John, V. (2011). Your guide to case study research. Pretoria: Van Schaik.

Sims, E. (2006). A new shape for schooling? Deep learning - 1: Specialist schools and academics trust. London, England: Impact Solutions.

Sternberg, R. J., \& Zang, L. F. (2000). Perspectives on cognitive, learning, and thinking styles. Cleveland: N.J. Lawrence Erlbaum.

Wang, L. (2006). Sociocultural learning theories and information literacy teaching activities in higher education. American Library Association, 47(2), 149-159.

Weltman, D. (2007). A comparison of traditional and active learning methods: An empirical investigation utilizing a linear mixed model (Unpublished doctoral dissertation). The University of Texas, Arlington, Texas.

Wenger, E. (2012). Communities of practice: A brief introduction. Wenger-trayner. Retrieved from http://wengertrayner.com/wpcontent/uploads/2012/01/06-Briefintroduction-to-communities-ofpractice.pdf. 